\title{
Editorial
}

\section{The Physical Therapy and COVID-19}

\author{
Zaid Al-Boloushi ${ }^{1,2}$ \\ ${ }^{1}$ Department of Physical Therapy, PMR Hospital Ministry of Health, \\ State of Kuwait \\ 2 iPhysio Research group, San Jorge University, Spain
}

Rev Fisioter Invasiva 2020;3:1.

The year 2020 had a different plan for our world. It affected everyone in different ways, uniting them while physically distancing them. It has been a new experience, one that is continuously testing people's wills, as well as their resilience and adaptability. Humanity, in an effort to protect itself from a microorganism called COVID-19, has given up on simple things that, in the past, were taken for granted, such as a hug or a handshake; we have learned to appreciate our health and our family more than ever. Schools and many businesses have closed in the effort to combat this new threat however, people have adapted and found new ways to move forward through different online platforms. Only time will determine what our world will look like once this pandemic passes.

What about physical therapists? What is our role during this pandemic? Do we have one? How can we help our countries and colleagues on the front lines? What can we do? Are we an essential part of the medical community that is confronting this global foe? These are just a few of the many questions that have arisen. Many of our colleagues have dedicated themselves in caring for seriously ill COVID-19 patients, working side by side with their medical colleagues at the ICU. Our forgotten colleagues are supporting the health care system and the ICU with their distinctive clinical skills. This dedication to their work must not go unacknowledged.

Many medical societies have introduced different online resources to continue training medical professionals at this time. For example, the Society of Critical Care Medicine has an online chapter targeting non-ICU clinicians as part of a backup plan to support the medical system from collapse. As part of its own initiative, the Australian Physiotherapy Association has also provided virtual training to its physical therapists who have had previous experience in intensive care to combat this growing health crisis. These are just a couple of examples of how health care systems worldwide have adapted to the current situation and the vital role of the physical therapist during the current health crisis.

Once the world begins to heal itself we will be faced with a new reality. Borders will start to reopen, economies will restart, people will be able to leave their homes, children will be able to go to school, families will enjoy picnics in the park....However, what lessons will we take from what we have been through? Much uncertainty remains however, one thing is certain, our world will not be the same as it was in 2019.

Here, at the Scientific Society of Invasive Physical Therapy and the Journal of Invasive Techniques in Physical Therapy, we are continuing our research, focusing on improving our patients' lives with new techniques for when we return to our clinics and hospitals while, always keeping in mind, the necessary precautions to protect both them and ourselves from the virus that has become, and will continue to be, a part of our daily life. We, like other health care professionals, treat patients who may cough or sneeze during a session which can cause respiratory droplets, so keeping safe is vital.

Minimally invasive therapy has been increasingly employed worldwide. Many studies have been published to support its effectiveness. Patients have improved using these invasive techniques. Our patients need us to restore their movement, to decrease musculoskeletal pain so they can lead pain free lives.

We will go back to work. The world will not stop ... and neither will we.
Address for correspondence Dr. Zaid Al-Boloushi, Master, P.O.Box, 66135, Bayan, Kuwait City, 43752 (e-mail: boloushi@gmail.com).
DOI https://doi.org/ 10.1055/s-0040-1713085. ISSN 2386-4591.
Copyright $\odot 2020$ by Thieme Revinter Publicações Ltda, Rio de Janeiro, Brazil 